Int. J. Odontostomat., 11(1):71-76, 2017.

\title{
Eficacia de Lidocaína $2 \%$ y Articaína $4 \%$ al usar la Técnica Infraorbitaria Modificada para Incisivos y Premolares Maxilares
}

\author{
Efficacy of $2 \%$ Lidocaine and $4 \%$ Articaine with the Modified Infraorbital \\ Nerve Block to Anesthetize Maxillary Incisors and Premolars
}

\author{
Adel Martínez Martínez; Maricela Agámez Romero ${ }^{1}$ \& Irlenis Martínez Rivera
}

MARTínEZ, M. A.; AGÁMEZ, R. M. \& MARTínEZ, R. I. Eficacia de lidocaína $2 \%$ y articaína $4 \%$ al usar la tecnica infraorbitaria modificada para incisivos y premolares maxilares.Int. J. Odontostomat., 11(1):71-76, 2017.

RESUMEN: Se realizó un ensayo clínico, aleatorizado, en el cual se determinó la eficacia de la técnica infraorbitaria modificada al usar de Lidocaína $2 \%$ y Articaína $4 \%$, para lograr anestesia pulpar exitosa en incisivos y premolares maxilares. Se realizó un estudio experimental, controlado doble ciego. 20 sujetos voluntarios recibieron 1,8 ml de Lidocaína $2 \%$ y Articaína $4 \%$ con epinefrina, en la técnica infraorbitaria modificada. Se utilizó un vitálometro para medir la anestesia pulpar exitosa en incisivos y premolares maxilares. El grado de anestesia pulpar fue considerada cuando el vitálometro alcanzó dos lecturas consecutivas a 80. Los participantes informaron además sobre anestesia de tejidos blandos y percepción de comodidad de dicha anestesia. Los datos se analizaron usando la prueba de Shapiro Wilk, Mann-Whitney y McNemar. Resultados: Se observó que en el 100 y $95 \%$ de los incisivos centrales, no hubo anestesia pulpar exitosa para el grupo de Articaína y Lidocaína respectivamente $(p=0,50)$. En el incisivo lateral, el $85 \%$ y $90 \%$ de los dientes presentaron igual comportamiento $(p=0,698)$. El canino presentó anestesia pulpar exitosa en el $70 \%$ de los casos para el grupo de Articaína y en el $40 \%$ para Lidocaína, datos estadísticamente significativos $(p=0,027)$. La anestesia de tejidos blandos fue del $100 \%$ y el $60 \%$ de los pacientes del grupo de articaína la refirieron como incomoda. Conclusiones. La técnica infraorbitaria modificada usando Articaína 4 \% o Lidocaína al $2 \%$ no es eficaz para lograr la anestesia pulpar en los incisivos centrales y laterales, demostrando tener una mejor tasa de éxito en caninos cuando se utiliza articaína. Los autores recomiendan anestesiar las ramas alveolares antero y medias superiores para lograr anestesia pulpar profunda en incisivos y premolares.

PALABRAS CLAVE: bloqueo nervioso, bloqueo nervio infraorbitario, anestésicos, anestesia pulpar, lidocaína, articaína.

\section{INTRODUCCIÓN}

Muchos autores han descrito que el bloqueo infraorbitario intraoral, es efectivo para proveer anestesia profunda en incisivos anterosuperiores y premolares. Sin embargo varios ensayos clínicos que evaluaron la eficacia del bloqueo infraorbitario intraoral, demuestran que la tasa de éxito anestésico en incisivos centrales y laterales oscila entre el 15 y $30 \%$ y que no se logra anestesia del $100 \%$ en caninos y premolares. Martinez Martinez (2009), Reed et al. (2012) y Gaudy \& Arreto (2006) describen la distribución anatómica del ramillete infraorbitario, refiriendo que este es el responsable de inervar tejidos blandos, piel, labios, y parpado inferior y no inerva los dientes anterosuperiores y premolares, quienes son inervados por los nervios alveolar antero superior y medio superior, respectivamente.

Berberich et al. (2009) evaluaron la eficacia del bloqueo infraorbitario intraoral, comparando lidocaína con epinefrina 1:100.000 y 1:50.000 con mepivacaína al $3 \%$, en cuarenta sujetos, los autores reportaron que la técnica infraorbitaria es ineficaz en proveer anestesia pulpar profunda de incisivos central, lateral y primer molar y que la tasa de éxito anestesico de canino, primer y segundo premolar oscilo en un rango entre el 75 al $92 \%$, al usar lidocaína al $2 \%$ con epinefrina $1: 100.000$ y 1:50.000. Katz et al. (2010) evaluaron la eficacia anestésica de lidocaína 2 \% con Epinefrina

${ }^{1}$ Departamento de Medicina Oral, Facultad de Odontología, Universidad de Cartagena, Cartagena, Colombia. 
1:100.000, prilocaína $4 \%$ con epinefrina 1:200.000 en infiltraciones maxilares del incisivo lateral y el primer molar, usando un vitalómetro. Sesenta sujetos recibieron 1,8 cc de cada solución anestésica. No hubo diferencias estadísticamente significativas en el éxito anestésico y en el inicio de la anestesia pulpar ninguno de los anestésicos proveo una hora de anestesia pulpar. Los autores recomendaban la infiltración de los incisivos maxilares para lograr un bloqueo adecuado de la rama alveolar anterosuperior.

\section{MATERIAL Y MÉTODO}

Se realizó un estudio experimental, controlado, doble ciego, en el que se determinó el grado de anestesia pulpar en incisivos, canino y premolares maxilares comparando lidocaína al $2 \%$ con epinefrina 1:80.000 y articaína $4 \%$ con epinefrina 1:100.000 usando la técnica infraorbitaria modificada. 20 sujetos voluntarios fueron incluidos en este estudio, donde se colocó la técnica infraorbitaria modificada y se realizó prueba de sensibilidad pulpar con vitalómetro (Analytic Technology, Redmond, WA, USA), en el incisivo central, lateral, canino y en los dos premolares; evaluando 100 dientes en total y realizando 1000 pruebas de vitalometria, a razón de 5 pruebas por cada diente en dos sesiones. Los investigadores solicitaron a una tercera persona que reemplazara la etiqueta de los dos cartuchos anestésicos por dos bandas de colores diferentes, de tal forma que los investigadores y los sujetos de estudio, desconocieran que solución anestésica se estaba usando. Cada sujeto recibió los dos principios activos, de forma aleatorizada, en sesiones separadas, con intervalo de una semana, a la misma hora y en el mismo cuadrante. La técnica anestésica fue colocada por el mismo investigador, el cual se escogió previo proceso de estandarización de la técnica anestésica, en un estudio piloto. Se realizó historia clínica completa y consentimiento informado, donde se verificaba los antecedentes que nos permitía determinar si el paciente cumplía con los criterios de inclusión. Inmediatamente después de colocada la técnica infraorbitaria de acuerdo a los criterios de Martínez, se inició el cronometro en 00. El test de sensibilidad pulpar con vitálometro, fue realizado en central, lateral, canino, primer y segundo premolar cinco minutos después de la inyección del anestésico y así consecutivamente a los 10,15, 25, 35 y 45 minutos post inyección como lo describe Gazal et al. (2015). Previamente los investigadores realizaron un test de control de vitalidad en el canino contralateral sin anes- tesia, con el ánimo de verificar el funcionamiento del vitálometro y para que el paciente analice como es la percepción que se tiene ante el estímulo eléctrico. El criterio que se tuvo para determinar si hubo anestesia pulpar exitosa fue que no existiera respuesta a la máxima estimulación (80) en dos o más lecturas consecutivas de acuerdo a lo expuesto por Kanaa et al. (2009), Berberich et al. y Lin \& Chandler (2008). El número de episodios de no respuesta a máxima estimulación fueron anotados en una tabla matriz. El número de episodios de respuesta a máxima estimulación fue tabulado en una tabla matriz. La anestesia de tejidos blandos fue evaluada, como la sensación objetiva al momento de realizar el test, el cual se realizó estimulando la encía, piel del ala de la nariz y piel del labio superior con un instrumento punzante, el sujeto respondió sí o no, al percibir el estímulo en cada una de las regiones anatómicas a evaluar. La comodidad de la anestesia de tejidos blandos fue evaluada como el nivel de comodidad que el sujeto refería ante la anestesia de la encía, piel del ala de la nariz y piel del labio superior, se interrogó a los 5 y 45 minutos, usando un test de evaluación subjetiva que permitió a los investigadores conocer si dicha sensación era incomoda, regular o cómoda.

\section{RESULTADOS}

Distribución por edades: El mayor número de sujetos tenían 22 años siendo el $25 \%(n=5)$, seguido del grupo etario de 21 y 24 años con un $20 \%(n=4)$ y el menor número de sujetos presentaron 19 años con un $5 \%(n=1)$ (Tabla I).

Tabla I. Distribución por edades

\begin{tabular}{lcc}
\hline Edad & Frecuencia & Porcentaje \\
\hline 19 & 1 & $5 \%$ \\
20 & 3 & $15 \%$ \\
21 & 4 & $20 \%$ \\
22 & 5 & $25 \%$ \\
23 & 3 & $15 \%$ \\
24 & 4 & $20 \%$ \\
Total & 20 & $100 \%$ \\
\hline
\end{tabular}

Distribución por sexo: El sexo femenino y masculino se distribuyó igualmente siendo el $50 \%(n=10)$ en ambos sexos IC: $95 \%$. (Tabla II).

Grado de anestesia pulpar: Al evaluar el grado de anestesia pulpar a nivel del incisivo central, este no 
Tabla II. Distribución por sexo

\begin{tabular}{lcc}
\hline Sexo & Frecuencia & Porcentaje (\%) \\
\hline Femenino & 10 & $50 \%$ \\
Masculino & 10 & $50 \%$ \\
Total & 20 & $100 \%$ \\
\hline
\end{tabular}

presentó anestesia pulpar profunda en el $100 \%$ de los casos en el grupo de articaína $4 \%$ con epinefrina 1:100.000, en el grupo de lidocaína al $2 \%$ con epinefrina 1:80.000 no se presentó anestesia pulpar profunda en el $95 \%$ de los casos, no encontrando diferencias estadísticamente significativas $(p=0,500)$. A nivel de los incisivos laterales, no presentaron anestesia pulpar profunda el $90 \%$ y $85 \%$ de los pacientes pertenecientes al grupo de lidocaína al $2 \%$ y articaína al $4 \%$ respectivamente, datos sin significancia estadística $(p=0,698)$. Con respecto al canino, el $70 \%$ $(n=14)$ de los dientes que pertenecieron al grupo de articaína presentaron anestesia pulpar profunda, mientras que en el grupo de lidocaína el $60 \%(n=11)$ presentaron dicha anestesia. En este caso hubo diferencias estadísticamente significativas al comparar los dos grupos $(p=0,27)$. El primer y segundo premolar presentó anestesia pulpar profunda, en el $85 \%$ y $75 \%$ de los caso en ambos grupos, mostrando diferencias estadísticamente significativas al comparar los dos grupos $(p=0,547)$ (Fig. 1).

Anestesia de tejidos blandos: Se encontró que el $100 \%(n=20)$ de los sujetos refirió anestesia de tejidos blandos a los 5 y 45 minutos tanto para lidocaína $2 \%$ con epinefrina 1:80.000 y articaína $4 \%$ con epinefrina 1:100.000 (Tabla III).

Evaluación de la percepción del paciente ante la anestesia de tejidos blandos: De forma global el 47,5 $\%$ de los sujetos, evaluaron la comodidad como regular. Al estratificar por grupos de tratamiento se encontró que el $25 \%$ de los sujetos $(n=5)$ la refirió como cómoda, $60 \%$ de los sujetos $(n=12)$ como regular, 15 $\%$ de los sujetos ( $n=3$ ) como incomoda en el grupo de articaína. Dentro del grupo de lidocaína el $65 \%$ de los sujetos $(n=13)$ la refirió como cómoda, $35 \%$ de los sujetos $(n=7)$ como regular, y ningún paciente la refirió como incomoda $0 \%(n=0)$ (Tabla IV)

Tabla III. Anestesia de tejidos blandos a los 5 y 45 minutos

\begin{tabular}{lcccccc}
\hline & \multicolumn{3}{c}{ Articaína $4 \%$} & \multicolumn{2}{c}{ Lidocaína $2 \%$} & Total \\
Sensación & $\mathrm{N}$ & $\%$ & $\mathrm{~N}$ & $\%$ & $\mathrm{~N}$ & $\%$ \\
\hline Cómodo & 5 & 25 & 13 & 65 & 18 & 45 \\
Regular & 12 & 60 & 7 & 35 & 19 & 47,50 \\
Incómodo & 3 & 15 & 0 & 0 & 3 & 7,50 \\
Total & 20 & 100 & 20 & 100 & 40 & 100 \\
\hline
\end{tabular}

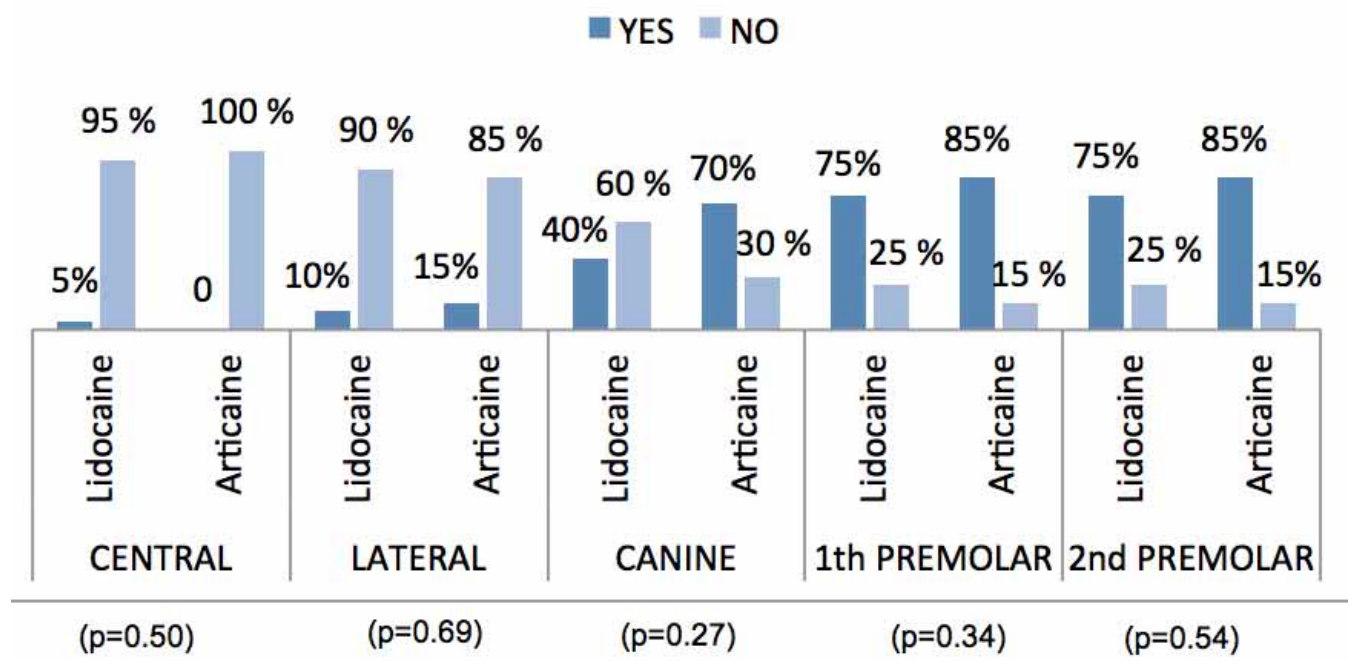

Fig 1. Grado de éxito en la anestesia pulpar. 
Tabla IV. Comodidad de la anestesia de tejidos blandos.

\begin{tabular}{lcccccc}
\hline & \multicolumn{2}{c}{ Articaína $4 \%$} & \multicolumn{2}{c}{ Lidocaína 2 \% } & Total & \\
Sensación & $\mathrm{N}$ & $\%$ & $\mathrm{~N}$ & $\%$ & $\mathrm{~N}$ & $\%$ \\
\hline Cómodo & 5 & 25 & 13 & 65 & 18 & 45 \\
Regular & 12 & 60 & 7 & 35 & 19 & 47,50 \\
Incómodo & 3 & 15 & 0 & 0 & 3 & 7,50 \\
Total & 20 & 100 & 20 & 100 & 40 & 100 \\
\hline
\end{tabular}

De forma cuantitativa al comparar el grado de comodidad ante la anestesia de tejidos blandos se encontró que para el grupo de articaína el promedio de comodidad fue $1,9 \pm 0,64$ y para el grupo de lidocaína fue de $1,35 \pm 0,48(p<0,001)$.

\section{DISCUSION}

Berberich et al. realizaron un ensayo clínico doble ciego para determinar la eficacia anestésica de lidocaína al $2 \%$ con epinefrina 1:100.000, lidocaína al $2 \%$ con epinefrina 1:50.000 y mepivacaína al $3 \%$, en el bloqueo infraorbitario. Cuarenta sujetos fueron enrolados en este estudio para recibir el bloqueo infraorbitario con las tres soluciones anestésicas en citas separadas, con espacios de una semana entre cada cita, se usó un cartucho completo $(1,8 \mathrm{cc})$ y se evaluaron los incisivos, premolares y primer molar maxilar con un vitalómetro, a razón de cuatro ciclos durante 60 minutos. A pesar de que dicho estudio evaluó la técnica infraorbitaria convencional y la población fue mayor al presente, los resultados, al igual que este reporte, demostraron que la técnica infraorbitaria es ineficaz en proveer anestesia pulpar profunda de incisivos central, lateral, siendo la tasa de éxito de la anestesia de canino, primer y segundo premolar, entre el 75 al $92 \%$, al usar lidocaína al $2 \%$ con epinefrina 1:100.000 y 1:50.000, mientras en este estudio la tasa de éxito a nivel de canino fue del $40 \%$, primer y segundo premolar fue de 75 y $85 \%$ respectivamente, al usar lidocaína al $2 \%$ con epinefrina 1:80.000.

Mason et al. (2009) realizaron un ensayo clínico, aleatorizado doble ciego en 60 sujetos donde compararon la eficacia anestésica luego de infiltrar el incisivo lateral y primer molar maxilar con lidocaína $2 \%$ epinefrina en diferentes concentraciones; 1:100.000, 1:50.000 y mepivacaína $3 \%$ sin vasoconstrictor, usando vitalómetro para determinar el éxito anestésico pulpar. No encontraron diferencias significativas en cuanto al inicio de la anestesia y la tasa de éxito anestésico pulpar al comparar las diferentes concentraciones del anestésico. En el presente estudio los autores evaluaron dos principios activos lidocaína al $2 \%$ y articaína $4 \%$ con concentraciones diferentes de epinefrina; 1:80.000, 1:100.000, no encontrando diferencias significativa al evaluar la tasa de éxito anestésico pulpar en el incisivo lateral, por lo que se presume que la concentración del vasoconstrictor no influyo en el éxito anestésico pulpar, a pesar de que dicho estudio evaluó una técnica troncular del maxilar superior.

Ensaldo et al. (2003) realizaron un estudio de 86 sujetos donde 43 fueron anestesiados con articaína al 4 $\%$ con epinefrina 1:100.000, mientras los otros 43 con lidocaína al $2 \%$ con epinefrina 1:100.000, cuyo propósito fue comparar el efecto anestésico entre la lidocaína y la articaína. La Articaína demostró ser un anestésico efectivo y seguro para todos los procedimientos dentales, el efecto anestésico de la lidocaína llegaba a un nivel parecido de anestesia, pero los sujetos anestesiados con la articaína reportaban un efecto más profundo y rápido, claramente dicho estudio al igual que este, corrobora que el grado de eficacia de la articaína en comparación de la lidocaína es levemente mayor, con una diferencia de $85 \%$ - $75 \%$ respectivamente.

Karkut et al. (2010) realizaron un estudio en 40 adultos para comparar la eficacia de la técnica infraorbitaria abordaje extra oral e intraoral usando lidocaína $2 \%$ con epinefrina 1:100.000, se encontró que el bloqueo tanto extraoral como intraoral fue ineficaz en proveer anestesia pulpar profunda en incisivos centrales; $15 \%$ sucesos exitosos, en los laterales solo un 22 $\%$ de sucesos exitosos, mientras que la tasa de éxito en caninos fue del $92 \%$ y en premolares del $80-90 \%$ en primer y segundo premolar, sin encontrar diferencias estadísticas entre el bloqueo extra e intraoral; estos resultados son similares a este estudio en cuanto a la ineficiencia de la técnica infraorbitaria para anestesiar centrales y laterales, ya que la tasa de éxito fue de $0 \mathrm{y}$ $15 \%$ respectivamente usando articaína y $5-10 \%$ usando lidocaína. A nivel de caninos la tasa de éxito fue del $75 \%$ con la articaína y $40 \%$ con lidocaína, en primer y segundo premolar fue del $85 \%$ con articaína y $75 \%$ con lidocaína, lo que confirma en ambos estudios que la técnica infraorbitaria puede ser ineficaz para aneste- 
siar los centrales y laterales, siendo eficaz en la anestesia de premolares.

Los autores consideran que la técnica infraorbitaria usando ya sea articaína o lidocaína es ineficaz para lograr anestesia pulpar profunda en los incisivos maxilares, por lo que se debe tener en cuenta el uso de otras técnicas, como la técnica alveolar antero superior y media superior cuando se realiza un procedimiento en el sector anterior. La anestesia de tejidos blandos resulta más incómoda para el sujeto al usar el anestésico articaína al compararlo con la lidocaína, y lo predispone a sufrir de injurias en tejidos blandos, por lo que al usar la técnica infraorbitaria se hace necesario garantizar la recuperación completa de la sensibilidad de los tejidos blandos, antes de abandonar el consultorio.

\section{CONCLUSIONES}

Los autores consideran que la técnica infraorbitaria modificada al usar articaína al $4 \%$ con epinefrina 1:100.000 o lidocaína al $2 \%$ con epinefrina 1:80.000 no es eficaz para lograr anestesia pulpar profunda en incisivos centrales y laterales, demostrando tener una mejor tasa de éxito a nivel de canino y primer premolar maxilar, esto se explica porque se produce una anestesia por infiltración de la rama alveolar anterosuperior que discurre por la eminencia canina, sitio adyacente a la zona de punción y no por el bloqueo del ramillete infraorbitario como tal. Se encontraron diferencias estadísticamente significativas al comparar la lidocaína al $2 \%$ y la articaína al $4 \%$ en la técnica infraorbitaria modificada, en cuanto al grado de anestesia pulpar en el grupo de articaína, en la región de caninos y premolares, demostrando la capacidad de difusión que tiene este principio activo en el hueso maxilar y las ventajas que presume el usar dicha solución anestésica cuando de realizar procedimientos en la región canina y premolar maxilar se trata. Los autores recomiendan el bloqueo de las ramas alveolares antero y media superiores en procedimientos que impliquen los incisivos y premolares maxilares usando articaína al 4 $\%$ con epinefrina 1:100.000.

\section{AGRADECIMIENTOS}

Al Dr. Miguel Simancas por su aporte invaluable, en el análisis estadístico. Al grupo GITOUC en especial al Dr Antonio Díaz por su ayuda en la construcción del presente artículo.
MARTíNEZ, M. A.; AGÁMEZ, R. M. \& MARTÍNEZ, R. I. Efficacy of $2 \%$ lidocaine and $4 \%$ articaine with the modified infraorbital nerve block to anesthesize incisors and premolars. Int. J. Odontostomat., 11(1):71-76, 2017.

ABSTRACT: The aim of this study was to compare de degree of successful pulpal anesthesia in maxillary incisors and premolars applying the modified infraorbital anesthetic technique using $2 \%$ lidocaine and $4 \%$ articaine with epinephrine. An experimental study, controlled, doubleblind was conducted. 20 volunteer subjects received $1.8 \mathrm{ml}$ of $2 \%$ lidocaine and $4 \%$ articaine with epinephrine, in the modified infraorbital technique. An electric pulpal tester was used to measure the pulpal anesthesia in maxillary incisors and premolars. The participants informed the degree of pulpal anesthesia, soft tissue anesthesia and comfort. The data was analyzed using the Shapiro Wilk, Mann-Whitney and McNemar tests. The 100-85 \% of non-anesthetized cases was observed in the central incisors $(p=0.500)$ and $95-90 \%$ in the lateral incisors $(p=0.500)$ for articaine and lidocaine respectively. At a level of canines the degree of successful pulpal anesthesia for the $4 \%$ articaine group was $70 \%$ and for $2 \%$ lidocaine was $40 \%(p=0.027)$, differences were statistically significant. At a level of first and second premolars, the degree of successful pulpal anesthesia for the $4 \%$ articaine group was $85 \%$ and for $2 \%$ lidocaine was 75 $\%(p=0.347)$ The subjective incidence of the soft tissue anesthesia was $100 \%$ and $60 \%$ of the patients of the articaine group referred to it as uncomfortable. The modified infraorbital technique using $2 \%$ lidocaine or $4 \%$ articaine is not effective to achieve pulpal anesthesia in central and lateral incisors, showing a better success rate in canines when using $4 \%$ articaine. The authors recommend anesthetizing the anterior and middle superior alveolar branches to achieve successful anesthesia in incisors and premolars procedures.

KEY WORDS: modified infraorbital technique, pulp vitality test, lidocaine, articaine.

\section{REFERENCIAS BIBLIOGRÁFICAS}

Berberich, G.; Reader, A.; Drum, M.; Nusstein, J. \& Beck, M. A prospective, randomized, double-blind comparison of the anesthetic efficacy of two percent lidocaine with 1:100,000 and 1:50,000 epinephrine and three percent mepivacaine in the intraoral, infraorbital nerve block. J. Endod., 35(11):1498-504, 2009.

Ensaldo, C. E.; Ensaldo, C. E.; Rivas, M. R.; Ensaldo, F. E. \& Adler, S. S. Estudio clínico comparativo entre articaína y lidocaína. Rev. A. D. M., 60(6):212-8, 2003.

Gaudy, J. F. \& Arreto, C. D. Manual de Anestesia en Odontoestomatología. Barcelona, Elsevier, 2006.

Gazal, G.; Alharbi, A. M.; Al-Samadani, K. H. \& Kanaa, M. D. Articaine and mepivacaine buccal infiltration in securing mandibular first molar pulp anesthesia following mepivacaine inferior alveolar nerve block: A randomized, double-blind crossover study. Saudi J. Anaesth., 9(4):397-403, 2015. 
MARTíNEZ, M. A.; AGÁMEZ, R. M. \& MARTíNEZ, R. I. Eficacia de lidocaina $2 \%$ y articaina $4 \%$ al usar la tecnica infraorbitaria modificada para incisivos y premolares maxilares. Int. J. Odontostomat., 11(1):71-76, 2017.

Kanaa, M. D.; Whitworth, J. M.; Corbett, I. P. \& Meechan, J. G. Articaine buccal infiltration enhances the effectiveness of lidocaine inferior alveolar nerve block. Int. Endod. J., 42(3):238-46, 2009.

Katz, S.; Drum, M.; Reader, A.; Nusstein, J. \& Beck, M. A. A prospective, randomized, double-blind comparison of $2 \%$ lidocaine with $1: 100,000$ epinephrine, 4\% prilocaine with 1 : 200,000 epinephrine, and $4 \%$ prilocaine for maxillary infiltrations. Anesth. Prog., 57(2):45-51, 2010.

Karkut, B.; Reader, A.; Drum, M.; Nusstein, J. \& Beck, M. A comparison of the local anesthetic efficacy of the extraoral versus the intraoral infraorbital nerve block. J. Am. Dent. Assoc., 141(2):185-92, 2010

Lin, J. \& Chandler, N. P. Electric pulp testing: a review. Int. Endod. J., 41(5):365-74, 2008.

Martínez Martínez, A. Anestesia Bucal. Guía Práctica. Buenos Aires, Editorial Médica Panamericana, 2009. pp.65-74.

Mason, R.; Drum, M.; Reader, A.; Nusstein, J. \& Beck, M. A prospective, randomized, double-blind comparison of $2 \%$ lidocaine with 1:100,000 and 1:50,000 epinephrine and 3\% mepivacaine for maxillary infiltrations. J. Endod., 35(9):1173-7, 2009.

Reed, K. L.; Malamed, S. F. \& Fonner, A. M. Local anesthesia part 2: technical considerations. Anesth. Prog., 59(3):127-37, 2012.

\author{
Dirección para correspondencia: \\ Adel Martínez Martínez \\ Departamento de Medicina Oral \\ Facultad de Odontología \\ Universidad de Cartagena \\ Cartagena de Indias \\ COLOMBIA
}

Email: amartinezm4@unicartagena.edu.co

Teléfono: +5756698172 ext. 110

Recibido : 31-10-2016

Aceptado : 30-12-2016 